\title{
MENKES DISEASE AS A DIFFERENTIAL DIAGNOSIS OF CHILD ABUSE
}

\author{
Juliana Harumi Arita', Eliete Chiconelli Faria', Mirella Maccarini Peruchi', Jaime Lin ${ }^{3}$, \\ Marcelo Rodrigues Masruha ${ }^{4}$, Luiz Celso Pereira Vilanova ${ }^{5}$
}

According to a research project from North Carolina published in 2003, approximately 1,300 children experience severe or fatal head trauma as a result of abuse each year, and inflicted head injury is the most common cause of traumatic death in infancy ${ }^{1-3}$. The shaken baby syndrome as a form of child victimization was first reported in 1971 and describes a constellation of symptoms and signs that results from the violent shaking of a young child commonly producing subdural hematomas ${ }^{4,5}$. Infants presenting with impairment of consciousness, seizures, head circumference enlargement and subdural hematomas, along with no obvious etiology always prompt the pediatrician to make this possible diagnosis, ${ }^{5,6}$. However, some rare metabolic diseases can produce nontraumatic subdural hematomas mimicking shaken baby syndrome. For this reason, the pediatrician plays an important role on recognition of such pathologies not only to avoid a mistaken diagnosis of child abuse, but also to provide the adequate management.

We report a case of a child with Menkes disease whose clinical course, initially led to the diagnosis of shaken baby syndrome in the emergency setting.

\section{CASE}

A male infant was the only child born to healthy and non-consanguineous parents at 37 weeks of gestation. There was no familial history of neurological diseases. Birth weight was $3.2 \mathrm{~kg}(25-$ $50^{\text {th }}$ centile) and head circumference $34 \mathrm{~cm}\left(25-50^{\text {th }}\right.$ centile). Apgar scores were 8 and 9 ( 1 and 10 minutes). General and neurological examinations were normal. The neonatal period was uneventful.

At 3 month-old he had a hospitalization with pneumonia and developed upper gastrointestinal bleeding due to duodenal ulcers. During this period he presented the first episode of seizure characterized by left eye blinking and drooling.
The patient was admitted at the age of 9 month old at the emergency room of our service presenting repetitive clonic seizures. Neurological examination revealed a poor general condition and disability to fix on an offered object and smile. It was also observed diminished limb muscle tone, brisk deep tendon reflexes in the lower extremities with bilateral clonus. Fundoscopy revealed a pale optic disc. Head circumference was 49,5 $\mathrm{cm}$ (above $97,5^{\text {th }}$ centile).

Blood levels of glucose, electrolytes as well as renal and hepatic functions were normal. Cerebrospinal fluid cell count, protein and glucose were normal. A cerebral CT-scan showed a massive bilateral extra-axial accumulation of fluid (Fig 1) suggesting subdural hematoma. At this moment, a diagnosis of shaken baby syndrome was suspected and an extensive clinical investigation started.

There was neither any apparent situation that suggested unstable family situation, behaviour problems nor substance abuse. The gestation was desired by both parents.

Skeletal survey revealed metaphyseal spurs at the lower ends of long bones but no signs of fractures.

At general examination, pale skin and the short and sparse hair called attention. Microscopic examination of the hair revealed a pili torti pattern that completely modified the clinical diagnosis from a traumatic cause to a nontraumatic one of metabolic nature. The pili torti pattern is characteristic of Menkes disease (Figa 2A, 2B and 2C).

Further laboratory investigations showed plasma ceruloplas$\mathrm{min}$ at $5.9 \mathrm{mg} / \mathrm{dL}$ (reference value: 20 to $63 \mathrm{mg} / \mathrm{dL}$ ) and serum cooper below $25 \mathrm{mcg} / \mathrm{dL}$ (reference value: $140 \mathrm{mcg} / \mathrm{dL}$ ) confirming the diagnosis of Menkes disease.

The child presented clinical instability during internation and a magnetic resonance could not be performed in time. The hospital ethic commission approved this case report and the parents gave informed consent for publication.

\section{DOENÇA DE MENKES COMO DIAGNÓSTICO DIFERENCIAL DE ABUSO DE CRIANÇA}

Division of Child Neurology / Department of Neurology and Neurosurgery / Federal University of São Paulo, São Paulo SP, Brazil (UNIFESP-EPM): 'Resident, Division of Child Neurology, UNIFESP-EPM; ${ }^{2}$ Resident, Department of Radiology, Heliopolis Hospital, Sao Paulo SP, Brazil; ${ }^{3}$ Post-Graduate Researcher, Division of Child Neurology / Department of Neurology and Neurosurgery, UNIFESP-EPM; ${ }^{4}$ Associated Physician, Division of Child Neurology / Department of Neurology and Neurosurgery, UNIFESP-EPM; ${ }^{5}$ Professor and Chairman, Division of Child Neurology / Department of Neurology and Neurosurgery, UNIFESP-EPM.

Received 20 October 2008, received in final form 13 January 2009. Accepted 3 April 2009.

Dra Juliana Harumi Arita - Disciplina de Neuropediatria / Departamento de Neurologia e Neurocirurgia - Rua Botucatu 720 - 04023-900 São Paulo SP - Brasil.E-mail: julyarita@uol.com.br 

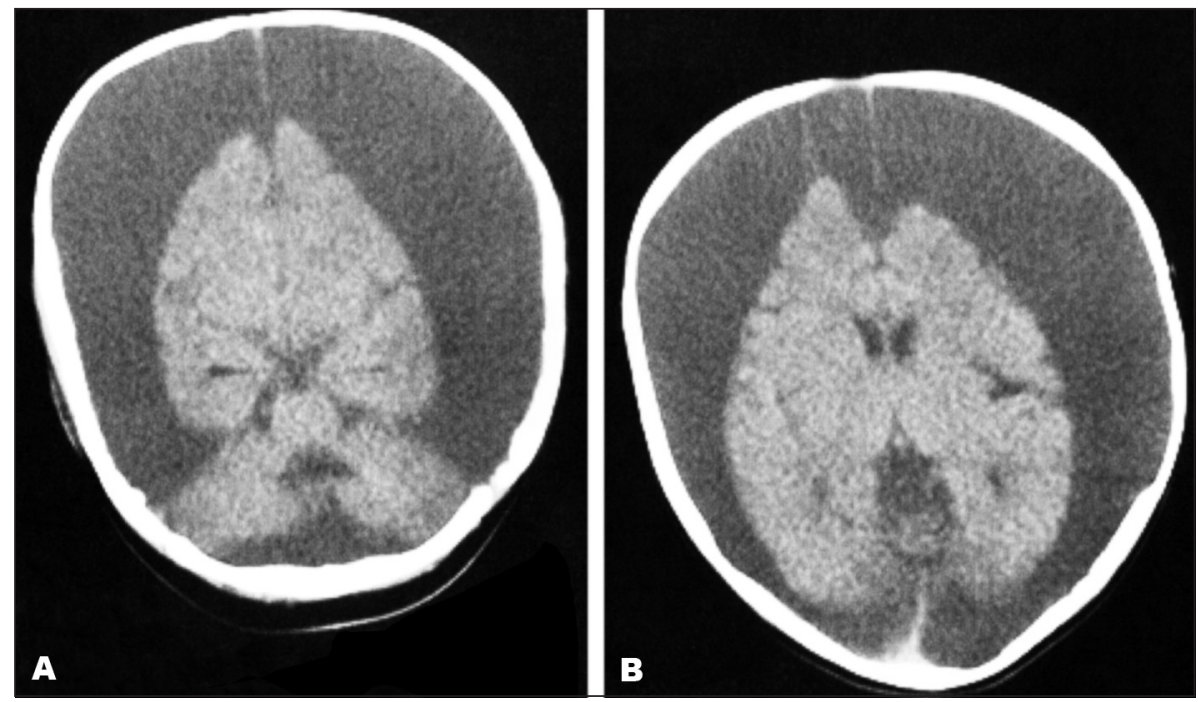

Fig 1. Axial non contrasted cerebral CT scan at three months, showing loss of gray-white matter differentiation. Extra-axial collection with higher attenuation than the cerebrospinal fluid, leading to parenchymal compression $[A, B]$.

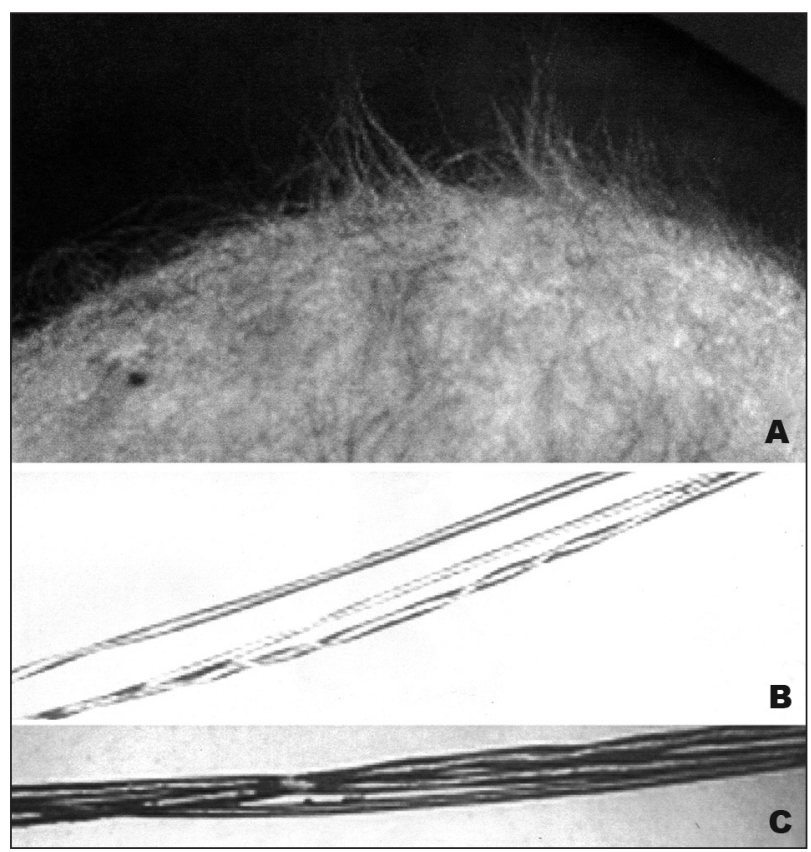

Fig 2. Patient's hair was short, pale and sparse [A], and presented the classic pili torti pattern $[B, C]$

\section{DISCUSSION}

Menkes disease was first described in 1962 as an Xlinked recessive neurodegenerative disorder ${ }^{6}$. The incidence of the disease is around one case for every 100,000 to 250,000 births $^{7}$.

The main clinical features make a triad of developmental delay, progressive neurologic degeneration and hair abnormalities that are considered unique and found only in this disease?

The human Menkes disease gene is located on chro- mosome X13.3 and encodes a copper-transporting P-type ATPase. The abnormal gene causes a failure of copper absorption with subsequent copper maldistribution and relative deficiency in certain tissues, especially serum, liver and brain. The characteristic clinical features are explained by the decrease in cuproenzyme activities (dopamine, $\beta$-hydroxylase, cytochrome-c oxidase, lysyl oxidase and sulfhydryl oxidase) $)^{6,8}$.

In several aspects, this case could be easily misinterpreted as child abuse. Poor general condition, hypotonia, macrocephaly and especially seizures in association with subdural hematomas and metaphyseal bone changes may result in a false diagnosis of battered child ${ }^{6}$. Other symptoms include lethargy, irritability, increased or decreased tone and impaired consciousness that are reported in 40 to 70 percent of patients ${ }^{3}$.

CT scanning is an important tool used in the diagnosis of the shaking-impact syndrome. In our case, although the images were similar to those found in shaken baby syndrome the addition of clinical findings were enough to make the diagnosis of Menkes disease, even in the absence of MRI scan. In Menkes disease, the origin of cerebral lesions is probably multifactorial; the abnormal copper metabolism might act directly on grey or white matter, or its primary effect might be to delay CNS development ${ }^{6}$.

Large subdural hemorrhages develop with progression of the disease with two factors being responsible for this complication. First, cerebral atrophy is frequent and believed to be due to reduced activity of the various copper containing enzymes resulting in elongation of the subdural bridging veins. Second, dysfunction of copper dependent lysyl oxidase induces a failure in elastin and col- 
lagen cross-linking. Veins become tortuous, with irregular lumen and frayed and split intimal linning. Recurrent subdural hemorrhages may develop spontaneously or as result of relatively minor head trauma ${ }^{6,9}$.

Even though child abuse must be on top of the differential diagnosis for all infants who present with seizures and subdural hemorrhages, extreme caution about making inferences must be taken and Menkes disease should be included in the differential diagnosis of unexplained subdural hematomas and neurological deficits ${ }^{5,6,8,10}$.

Careful clinical examination, including a search for hair and skin abnormalities and laboratory data should greatly facilitate the correct diagnosis.

\section{REFERENCES}

1. Keenan HT, Runyan DK, Marshall SW, Nocera MA, Merten DF, Sinal SH. A population-based study of inflicted traumatic brain injury in young children. JAMA 2003;290:621-626.

2. Trokel M, Wadimmba A, Griffith J, Sege R. Variation in the diagnosis of child abuse in severely injured infants. Pediatrics 2006;117:722-728.
3. Duhaime A-C, Christian CW, Rorke LB, Zimmerman RA. Nonaccidental head injury in infants - the "shaken baby syndrome". N Engl J Med 1998;338:1822-1829.

4. Tung GA, Kumar M, Richardson RC, Jenny C, Brown WD. Comparison of accidental and nonaccidental traumatic head injury in children on noncontrast computed tomography. Pediatrics 2006;118:626-633.

5. Lee A, So K, Fong D, Luk S. The shaken baby syndrome: review of 10 cases. HKMJ 1999;5:337-341.

6. Nassogne M-C, Sharrard M, Hertz-Pannier L et al. Massive subdural haematomas in Menkes disease mimicking shaken baby syndrome. Childs Nerv Syst 2002;18:729-731.

7. Agertt F, Crippa ACS, Lorenzoni PJ, et al. Menkes' disease. Arq Neuropsiquiatr 2007;65:157-160.

8. Santos LMG, Teixeira CS, Vilanova LCP, et al. Menkes disease: case report of an uncommon presentation with white matter lesions. Arq Neuropsiquiatr 2001;59:125-127.

9. Menkes JH. Subdural haematoma, non-accidental head injury. Eur J Pediatr Neurol 2001;5:175-176.

10. Kemp A. Subdural haemorrhage in infants: when are they nonaccidental? Current Paediatrics 2001;11:197-201. 